\title{
A Research on the Tourists' Perceived Evaluation and Management of Safety Risks for Tourism Cities: A Case study of HangZhou
}

\author{
DANG Qun ${ }^{a}$, WU Cha-zi ${ }^{b}$ \\ School of management, Xi'an University of Science and Technology, Xi an, Shanxi \\ Province, 710054 , China \\ aharrietdang0220@126.com, b453615907@qq.com
}

\begin{abstract}
Keywords: Tourism Cities, Travel safety, Perception of security risks, risk and safety management in Tourism.
\end{abstract}

Abstract. Travel safety is a guarantee to developing city tourism. Because of the frequent accidents during traveling, tourists become more concerned about tourism safety. This paper chooses Hangzhou as a research object, uses methods of Network Text Analysis, Grounded Theory, Expert Interview Method to construct the tourist testing system of Hangzhou's tourism safety and risks, and also carries on questionnaire surveys to the tourists who are in Hangzhou. The conclusions are as following: the overall evaluation of tourism safety in Hangzhou is high, but the assessment on shopping which belongs to six elements of tourism safety evaluation is general; social security and physical factor are the strongest among the tourists' perceptive factors of tourism safety risks in the city, Hangzhou. Among the six security risk perceptive factors of Hangzhou's tourism, strong elements are sequencing as follows: food hygiene, service levels of hotel staffs , management of hotel safety, driving skills of drivers, levels of traffic safety management, flow conditions of visitors, coercive consumption, and safety risks on existing recreation facilities. This paper puts forward the corresponding suggestions for the tourism safety management of Hangzhou from improving urban tourism safety public service level, aiming at security services for the six elements of tourism, and strengthening the guidance of tourists, so as to enrich the theoretical achievements of urban tourism safety management and provide references for urban managers to plan tourism safety services.

\section{Introduction}

Safety is the foundation of our life to meet basic needs of people. With the development of our society, tourism have developed to an advanced stage. Tourism safety is a comprehensive understanding of various safety hazard and mechanism, which helps to develop tourism healthily, aiming at putting forward the preventive measures.

Along with the development of tourism activities, tourists seek for higher safety requirements and rapid transmissions of information in the Internet information age that makes traveler pay more attention to the issue of tourism safety. Tourist city is one of the most important attractions to visitors in a region. Therefore, the significant and research have become a focus on urban tourism security.

At present, domestic and foreign countries launched a wide range of researches on tourist security. These researches mainly talked about tourism security (Foreign scholars, Mansfeld and Pizam, 2006, believed that it could be divided into three situations to explain that. The first one was associated with the nature of safety incidents or a crisis events during traveling, the second one was related to the impact on safety incidents or a crisis events of tourism, tourists and tourist communities and the last one was connected with the short-term, medium-term or long-term responses of stakeholders to safety incidents or crisis events in tourists' destinations. The Theory of Tourism Security, 2003, is the first literary work written by a scholar, ZHENG Xiang-min , in China. Domestic scholars,HU Hua and SONG Bao-pin, considered that tourists preferred different level of risks and also had different shopping risk perceptions.); perceived risks on tourism security (Leppa and Gibson, 2003, researched the perceived risks on tourism security of international tourists from 6 aspects which are health, political turbulence, terrorism, food, cultural conflict, and politics, religion, policy and crime. In our country, CHEN Jin-hua Chen and others used 6 dimensions, food, accommodation, 
transportation, traveling, shopping, and entertainment to emphasize on perception of tourism security in practical researches about visitor of the island, Meizhou. Zou Yong-guang and ZHNEG Xiang-min established a testing model for tourist security of their destinations based on Oliver's expectancy disconfirmation theory.); and risk management for tourism safety (The foreign scholar, Snmez believed that tourist destinations should have systematical crisis managements and crisis plans in order to protect and re-establish theirs attractions after disasters. Roehl and Fesenmaier, 1992, suggested developing cities' images through advertising so as to reduce tourists' Insecurity. In our country, KONG Bang-jie explained the basic elements and basic methods of tourism safety management from the perspective of relationship between tourism safety risk factors and the tourism system in his book, Tourism Safety Management.). It caused many problems about tourism safety in a lot of cities because research findings aiming at risk evaluation were not many. This research is aimed at evaluating perceived risks on tourism security of tourists based on a famous domestic city, Hangzhou, and puts forward some feasible measures of safety management which were able to provide some references to improve the level of tourism safety management in Hangzhou.

\section{Data collection and the establishment of tourists' perceived evaluation index system for security risks of Hangzhou}

This paper takes a famous tourist city, Hangzhou, as an example. Hangzhou, located in southeast coastal areas of China, is the capital of Zhejiang Province and is a very noted tourist city with many well-known natural and cultural tourism resources.

In this paper, firstly, we screened out 58 reviews of Hangzhou tourism safety network evaluation text through the four travel websites including TripAdvisor, Ctrip, Dianping, and Sina micro-blog, using ROST-CM6 software for word frequency analysis to get the table (Table 1). On the basis of word frequency analysis, we uses the grounded theory to decode and form preliminary investigation index.

Table 1 Frequency of sample words

\begin{tabular}{|c|c|c|c|c|c|c|c|c|c|}
\hline word & Number & word & Number & word & $\begin{array}{c}\text { numbe } \\
\mathrm{r}\end{array}$ & word & number & word & number \\
\hline safe & 40 & action & 7 & $\begin{array}{l}\text { dining } \\
\text { room }\end{array}$ & 4 & reception & 4 & manger & 3 \\
\hline travel & 26 & fire protection & 6 & complain & 4 & Supervise & 3 & Practice & 3 \\
\hline Service & 14 & Fight & 6 & Weather & 4 & Government & 3 & Handle & 3 \\
\hline West Lake & 13 & implement & 6 & Improve & 4 & Park & 3 & Time & 2 \\
\hline Check & 13 & Emphasize & 6 & lakeside & 4 & Sudi & 3 & Represent & 2 \\
\hline restaurant & 11 & Department & 6 & system & 4 & Main part & 3 & Conference & 2 \\
\hline Staff & 11 & Tourist & 6 & $\begin{array}{l}\text { Tourist } \\
\text { office }\end{array}$ & 4 & Technology & 3 & Identity & 2 \\
\hline facility & 10 & Policy & 6 & Market & 4 & accountability & 3 & Guest & 2 \\
\hline Hangzhou & 10 & Guesthouse & 5 & Train & 4 & People & 3 & Guide & 2 \\
\hline Enterprise & 10 & Development & 5 & Karma & 4 & Propaganda & 3 & Hospital & 2 \\
\hline Food & 9 & Measures & 5 & Toilet & 4 & Transaction & 3 & Contain & 2 \\
\hline Travel Agency & 8 & Clean & 5 & Quality & 4 & Entertainment & 3 & Operation & 2 \\
\hline Transport & 8 & Specification & 5 & Advice & 4 & Lifter & 3 & Aim & 2 \\
\hline Problem & 8 & Refine & 5 & Formulate & 4 & Manage & 3 & mechanism & 2 \\
\hline Room & 8 & Location & 5 & Control & 4 & drill & 3 & advance & 2 \\
\hline Scenic spot & 8 & Prompt & 5 & Spirit & 4 & Handle & 3 & Employee & 2 \\
\hline Administrate & 7 & construction & 5 & Whole & 4 & $\begin{array}{l}\text { Broken } \\
\text { Bridge }\end{array}$ & 2 & $\begin{array}{c}\text { The } \\
\text { homeless }\end{array}$ & 2 \\
\hline Develop & 7 & Investigate & 5 & Convince & 4 & Represent & 2 & Drive & 2 \\
\hline Special & 7 & Focus & 5 & Urgent & 4 & Conference & 2 & Fire & 2 \\
\hline Combination & 7 & Organization & 4 & $\begin{array}{c}\text { Tourism } \\
\text { law }\end{array}$ & 4 & Must & 2 & wallet & 2 \\
\hline Local & 7 & security & 4 & Hygiene & 4 & Notice & 2 & carry out & 2 \\
\hline Environment & 7 & Push & 4 & Eat & 4 & Guest & 2 & Expensive & 1 \\
\hline Hotel & 7 & Private taxi & 4 & Traffic & 4 & Instruction & 2 & Car & 1 \\
\hline
\end{tabular}


According to the core of perceived risks on tourism security, firstly, we cut down on works, extracted the concepts and classified them into 46 primary categories as risk factors. And then, we selected 12 as main categories of risk source framework from the 46. They were individual, food, social environment, natural environment, entertainment, health risks, time risks, satisfaction risks, accommodation, transportation, shopping, and scenic tours. Based on the correlation among the 12 main categories above and tourists who came to Hangzhou, we summarized the structure of perceived risks on tourism security and extracted three core categories that could cover most of the perceived risks on tourism security then. They were assessment on tourism safety of Hangzhou, the structure of perceived risks from tourists' views, the structure of 6-element risk security.

Out of lack of testing, we used methods of interviewing experts to analyze the integrity of the evaluation index constructed by grounded theory through net text. We interviewed four persons during Apr. 10th-15th, 2017. According to experts' opinions, we deleted two original indicators witch are tourism law and tourism supervision, and we also perfected words which had been used to describe indicators. And finally we obtained the tourists' evaluation index of tourism safety and risk perception about Hangzhou.

\section{Questionnaire Design and Survey}

\section{Questionnaire design and distribution}

The formal questionnaire was designed into four parts based on the evaluation index system that had been constructed. The first is the tourists' evaluation of tourism safety against Hangzhou which used Likert scale method. We applied multiple-choice ways to design tourists' perception of the risk factors of urban tourism safety against Hangzhou' and 'tourists' perceptions of the risk factors of six Tourism factors against Hangzhou' in order to perceive intensity with frequency response. In the end, we investigated in the demographic characteristics of samples.

During April 28th-30th, 2017,we issued 100 questionnaires in Hangzhou, and collected 100 questionnaires on line at the same time. A total of 200 questionnaires were distributed, 186 were recovered and the number of valid questionnaires were 184 . The recovery rate was $93 \%$ and the effective rate was $92 \%$. This paper used software spss 21.0 to count, analyze, and arrange the data of questionnaires, and used Cronbach's coefficient, $\alpha$, to test the reliability of questionnaires. The demographic characteristics of valid samples are shown in Table 2. 
Table 2 Sample characteristics

\begin{tabular}{|c|c|c|c|}
\hline & Basic information & Number & Ratio \\
\hline \multirow{2}{*}{ Gender } & Male & 106 & 57.0 \\
\hline & Female & 78 & 53.0 \\
\hline \multirow{6}{*}{ Age } & Under 18 & 27 & 14.7 \\
\hline & $18-25$ & 60 & 31.7 \\
\hline & $26-30$ & 65 & 34.4 \\
\hline & $31-40$ & 28 & 15.2 \\
\hline & $41-60$ & 2 & 1 \\
\hline & Over 60 & 2 & 1 \\
\hline \multirow{5}{*}{ Education level } & High school and below & 31 & 16.5 \\
\hline & & & \\
\hline & junior college & 67 & 36.4 \\
\hline & bachelor degree & 65 & 34.6 \\
\hline & Master and above & 21 & 11.2 \\
\hline \multirow{4}{*}{ Salary } & under 3000 & 125 & 67.9 \\
\hline & $3001-5000$ & 38 & 20.7 \\
\hline & $5001-10000$ & 10 & 5.4 \\
\hline & Over 10000 & 11 & 5.9 \\
\hline \multirow{10}{*}{ Job } & Business staff & 57 & 30.9 \\
\hline & & & \\
\hline & Civil servant & 12 & 6.3 \\
\hline & teacher & 13 & 6.8 \\
\hline & Self-employment & 24 & 12.8 \\
\hline & Student & 42 & 22.8 \\
\hline & Farmer & 1 & 0.5 \\
\hline & Retired & 5 & 2.7 \\
\hline & Freelancer & 25 & 13.6 \\
\hline & other & 5 & 2.7 \\
\hline
\end{tabular}




\section{Questionnaire reliability analysis}

This paper used statistical software, SPSS21.0 to calculate the alpha factor for each part of questionnaires based on 0.7 as the reliability standard which was proposed by Peterson, 1994. Details of the specific parts of questionnaires are shown in Table 3.

\begin{tabular}{lcc} 
& Table 3 Surveillance project \\
\hline Assessment on tourism safety of & Number & Cronbach's Alpha \\
Hangzhou & 7 & 0.812 \\
Structure of perceived risks from & 13 & 0.823 \\
tourists' views & 29 & 0.857 \\
Structure of 6-element risk security & & \\
\hline
\end{tabular}

From Table 3, we can see that each number of Cronbach's Alpha is bigger than the standard, one, 0.7. That means a strong internal consistency existing among questions.

Tourism safety evaluation based on tourists' perception in Hangzhou

This part regards the average value of tourists' assessments as the basis for evaluation, detailed in Table 4.

Table 4 Level of security risks for tourist place

\begin{tabular}{llllll}
\hline Security level & Very insecure & Insecure & general & Secure & Very secure \\
\hline Range & {$[1,1.5)$} & {$[1.5,2.5)$} & {$[2.5,3.5)$} & {$[3.5,4.5)$} & {$[4.5,5]$}
\end{tabular}

This paper analyzed the overall evaluation of tourism safety and the evaluation of tourism six elements of Hangzhou. As shown in Table 5, the score of overall evaluation about Hangzhou tourism safety risk is 4.1, and visitors give Hangzhou a high assessment of security about tourism environment. The six elements of tourism safety evaluation are very different. Hangzhou has a high rate of accommodation and food, at 3.98 and 3.86 respectively. The traffic safety, travel safety and entertainment security are slightly lower, at 3.74, 3.68, 3.66, which keep at a safe level. Shopping has the lowest score, only 3.42, which shows the the largest standard deviation up to 0.993 , reflecting the tourists on shopping in general, while the evaluation of the shopping part polarizes. The average value of tourist safety perception is 3.72 , which is maintained at a relatively safe level, but there is a big gap with the overall evaluation score, indicating that the urban tourism safety management should be based on the safety management of the tourism six elements system. Details are in Table 5.

Table 5 Evaluation of tourism safety risks about Hangzhou

\begin{tabular}{lccll}
\hline Safety evaluation & Minimum & Maximum & Average & $\begin{array}{l}\text { Standard } \\
\text { deviation }\end{array}$ \\
\hline Overall & 1 & 5 & 4.1 & 0.877 \\
Food & 1 & 5 & 3.98 & 0.935 \\
accommodation & 1 & 5 & 3.86 & 0.882 \\
transportation & 1 & 5 & 3.74 & 0.843 \\
Travel & 1 & 5 & 3.68 & 0.796 \\
Shopping & 2 & 5 & 3.42 & 0.993 \\
Entertainment & 1 & 5 & 3.66 & 0.875 \\
Average & 1 & 5 & 3.72 & \\
\hline
\end{tabular}

\section{Source structure and factor type based on the tourists' perceived tourism safety risk of Hangzhou}

The questionnaire reflected the perception and intensity of the source structure and the type of factors on tourists' risk of tourism about Hangzhou. As shown in Table 6, among the perceived social environmental risk factors, tourists pay more attention to social security whose perceived frequency is higher than others, accounting for $41.3 \%$. We also can see that tourists are more concerned about stealing (35.6\%)which is only lower than social security. Political turmoil (5.4\%) as well as terrorist attacks $(5.3 \%)$ perceive lower frequency. Among the natural environment factors, the tourists think that frequency of climatic conditions such as perceived intensity $(21.5 \%)$ is high, and perceived frequency of natural disasters $(18 \%)$ is low. Among the health risk factors, one fifth visitors think that medical facilities and infectious diseases are risk. Among the risk factors for individuals, $46.4 \%$ of 
tourists' risk perception comes from their physical condition, followed by lack of safety awareness (34\%) and cultural language(19.7\%). Among the time risk factors, more than $20 \%$ of the tourists risk comes from flight delays (22.9\%). Among the satisfaction risk, $30.3 \%$ of the tourists' risk perception comes from that the purchase of products do not meet their expectations. Specific data are in Table 6.

Table 6 Tourists' perception of source structure and risk factor about Hangzhou

\begin{tabular}{clcc}
\hline Structure & Factor & Frequency & Ratio (\%) \\
\hline Social environment & Political turmoil & 11 & 5.4 \\
& Terrorist attacks & 10 & 5.3 \\
& Social Security & 76 & 41.3 \\
& Stealing & 67 & 35.6 \\
Natural environment & Natural disasters such as & 34 & 18.0 \\
& typhoons & & \\
& Climatic conditions such as air & 41 & 21.5 \\
Health risk & quality & & \\
& Medical condition & 42 & 22.2 \\
Individual & Infectious disease & 40 & 21.3 \\
& Cultural barriers, language & 37 & 19.7 \\
& barriers & & 34.0 \\
Time risk & Lack of safety awareness & 64 & 46.3 \\
Satisfaction risk & Weak physical fitness & 87 & 22.9 \\
\hline
\end{tabular}

\section{Safety risks of six elements based on tourists' perception}

This paper came out with perceived intensity through analyzing the specific safety risk factors of six elements in the tourism, accommodation, transportation, traveling, shopping and entertainment.

In the food sector, tourists think that main risks mostly come from the food hygiene at a proportion of $65.4 \%$, followed by restaurant staff operating health status $(38.4 \%)$ and individual acclimatization $(33 \%)$. While the frequency of restaurants' environmental quality $(22.3 \%)$ and the level of safety management $(17.1 \%)$ are at a low level.

About accommodation part, nearly half of the tourists' risk perception comes from the hotel staffs' service level and hotel safety management, the proportion of which are $47.3 \%$ and $45.2 \%$, followed by the health conditions and facilities with ratios, $29.8 \%$ and $21.8 \%$. The lowest frequency of perception is the hotel environment, accounting for $18.6 \%$ only.

In the transportation part, the highest perception of tourists' perceived risk is drivers' driving skill and traffic safety management, accounting for $41.5 \%$ and $40.4 \%$ respectively, followed by traffic market chaos with the proportion of $35.1 \%$. Other perceived risk factors like poor road condition and congestion, or conditions of lack of guidepost as well as warning signs also have a certain proportion which are $18.6 \%$ and $18.1 \%$.

In the process of traveling scenic spots, the tourists are more worried about the crowded situation, accounting for $40.9 \%$, followed by safety signs and safety facilities of scenic area , accounting for $35.6 \%$ and $30.9 \%$. For the scenic environment, $23.9 \%$ of the tourists consider it as a source of risk factors. The perceived frequency of the service level is low, only $18.6 \%$. In the shopping process, visitors believe that forced to shopping and buying inferiors, counterfeits, expensive goods is the main risk factors, accounting for $69.1 \%$ and $60.1 \%$ respectively, followed by staffs' fraud $(28.8 \%)$ and purchase of illegal goods and shop facilities (18.6\%)at the shopping points.

In the process of entertainment, most of the visitors believe that potential safety hazards of recreation facilities $(52.1 \%)$ and the crowded of amusement places $(40.9 \%)$ is the main risk factors, as more than one third of the people (34.6\%) are worried about the level of protection , and $18.6 \%$ visitors concern about the level of staffs' safe operation. Details are in Table 7. 
Table 7 Perceived safety risks of six elements

\begin{tabular}{|c|c|c|c|}
\hline source & factor & frequency & ratio $(\%)$ \\
\hline \multirow{6}{*}{ Food } & No standardized operation of the staff & 72 & 38.3 \\
\hline & Acclimatization & 62 & 33.0 \\
\hline & Poor food's hygienic condition & 123 & 65.4 \\
\hline & Restaurant's poor environmental quality & 42 & 22.3 \\
\hline & Restaurant's poor safety management & 32 & 17.1 \\
\hline & Hotel staff's poor service level & 89 & 47.3 \\
\hline \multirow[t]{4}{*}{ Accommodation } & Poor hotel hygienic condition & 56 & 29.8 \\
\hline & Poor hotel environmental quality & 35 & 18.6 \\
\hline & Poor hotel facilities & 41 & 21.8 \\
\hline & $\begin{array}{l}\text { Level of hotel safety management } \\
\text { situation }\end{array}$ & 85 & 45.2 \\
\hline \multirow[t]{5}{*}{ transportation } & Poor driver’s driving skill & 78 & 41.5 \\
\hline & $\begin{array}{l}\text { Poor road conditions and road } \\
\text { congestion }\end{array}$ & 35 & 18.6 \\
\hline & Lack of road signs and warning signs & 34 & 18.1 \\
\hline & Traffic market chaos & 66 & 35.1 \\
\hline & Poor traffic safety management & 76 & 40.4 \\
\hline \multirow{5}{*}{$\begin{array}{l}\text { Traveling of } \\
\text { scenic spot }\end{array}$} & Scenic staff's poor service & 35 & 18.6 \\
\hline & Poor scenic environment & 45 & 23.9 \\
\hline & Lack of Scenic safety signs & 67 & 35.6 \\
\hline & The flow of people & 77 & 40.9 \\
\hline & Secure facilities in poor condition & 58 & 30.9 \\
\hline \multirow[t]{5}{*}{ Shopping } & Secure facilities in poor condition & 35 & 18.6 \\
\hline & Forced to shopping & 130 & 69.1 \\
\hline & Inferiors, counterfeits, expensive goods & 113 & 60.1 \\
\hline & Fraud & 56 & 29.8 \\
\hline & Purchase illegal goods & 35 & 18.6 \\
\hline \multirow[t]{4}{*}{ Entertainment } & Poor safety protection & 65 & 34.6 \\
\hline & $\begin{array}{l}\text { Potential safety hazards of recreation } \\
\text { facilities }\end{array}$ & 98 & 52.1 \\
\hline & The flow of people & 77 & 40.9 \\
\hline & Poor operation & 35 & 18.6 \\
\hline
\end{tabular}

Risk management for tourism safety based on tourists' perception in Hangzhou

\section{Safety needs based on tourists in Hangzhou}

Visitors have a clear attitude on evaluation and perception towards tourism security level. Its characteristics and needs on tourism safety include followings. (1) Tourists' overall assessment of safety towards Hangzhou tend to be very safe, showing a high degree of recognition. Safety 
evaluations on food, accommodation, transportation, traveling and entertainment are also high in a relative safe level. But most of tourists think shopping general safe. The comments are polarized and the mean value of the six elements is less than the overall evaluation. Therefore, risks should be control based on the six elements systematically. (2) Tourists' risk perception comes from social environment, natural environment, health risks, individual, time risk and satisfaction risk. Among them, the highest frequency of the source about risk factors is the situation of social security and the physical condition of the tourists themselves. That means a city's public security situation determines the tourists' awareness on their tourism safety risk mostly. (3) Among the six elements of tourism, the perceived frequencies about the hygienic condition in food part, hotel staff service level and hotel safety management in accommodation part, drivers' driving skill and traffic safety management level in transportation part, the flow of people in traveling part, being forced to buy fake and shoddy goods in shopping part, potential safety hazards of recreation facilities and the flow of people in entertainment part are high. Tourism six elements are changeable and complex, therefore, we should establish a management system according to specific factors.

\section{Construction of tourism safety management system against Hangzhou}

For the aspect of evaluation attitude and risk perception structure towards tourists in Hangzhou, when establishing urban tourism safety management system, we should base on the promotion of the urban tourism public safety service level. At the same time, we must focus on the construction of security system through tourism six elements, besides, we also must focus on leading tourists, which is particularly important.

\section{Improving the level of urban tourism safety public service}

In the aspect about safety risk perception of tourists, social security has a high frequency, for which we should focus on enhancing the integration of urban security public service level about tourism safety management. Hangzhou is a city with high level of Internet technology, therefore, through setting up urban intelligent security system, we can use specialized travel apps to monitor people flow as well as inquire credit investment, under the situation of too many tourists. We provide tourism emergency call, emergency feedback and other things which can help tourists through WeChat public numbers and also can help visitors to contact with relevant departments in a short time. Through investigation, collecting data about tourists can provide tourism sectors scientific evidence in fields of allocating tourism resources, improving tourism safety facilities and increasing staff number.

Establish crisis early warning mechanism as well as emergency mechanism. The so-called crisis early warning mechanism is an operating system that utilizes some high-tech means, through collecting warning index of industry or commercial crisis to capture information, and then takes pre-planned measures to resolve crisis according to results from crisis identification. The uncertainty of tourism industries has led to the urgency of the crisis early warning mechanism. Hangzhou is a city located in coastal provinces, with a lots of typhoons as well as other natural disasters which influence tourism development deeply. Tourism management departments can accurately and timely report typhoons, rainstorms and other natural disasters through cooperating with meteorological departments.

Enhance the construction of public safety infrastructure in tourist cities. Although it is difficult to change the fixed basic hardware facilities such as roads in tourism city Planning, we can adjust details in order to meet customers' needs, for example, increasing the number of road warnings and road signs against increased self-driving journey in case of lost.

\section{providing safe services for tourism six elements}

In order to protect property security, health risks and psychological needs of tourists in Hangzhou, we should provide safe service to meet six elements from food, accommodation, transportation, traveling, shopping and entertainment. Seen from the source of risk perception of tourists in Hangzhou, the most important thing is to ensure that the shopping part guarantees tourists' autonomy and products which have been brought are at a low price without fake and shoddy to harm tourists. The specific measures are recommended as follows:

(1) Food. About food part, tourists think highly of food hygiene and staffs' operation level, and they are also worried about acclimatization. Therefore, the industrial and commercial department should 
inspect food hygiene status and operational sanitary conditions of restaurants around big scenic spots. Department also should recommend more food with features of Hangzhou at propaganda windows and suggest emergency treatments on acclimatized situation.

(2) Accommodation. About accommodation part, tourists in Hangzhou are more worried about the hotel's safety management as well as sanitary conditions, therefore, we should check hotels regularly on safety management. On one hand, we should check that whether safety facilities are complete, on the other hand, we should check public sanitary status and disinfect regularly because of huge amount of mosquitoes. We are supposed to improve software services levels to provide humanistic service as far as possible in the existing infrastructure.

(3) Transportation. About situation of traffic chaos in Hangzhou, visitors reflect problems such as hard to take a taxi and charging ridiculous fees. These problems can be solved by posting taxi fare patterns as well as bus route maps at crowded places, encouraging people who stay in Hangzhou more then 5 days applying for Hangzhou transportation IC card. We should be aware of safe driving and speed limitation, refuse illegal behavior just like roundabout to protect tourists' physical safety and psychological safety. For the problem of private taxis, we should increase inspections and clampdowns.

(4) Traveling. Hangzhou is an international tourist city and each year there are a large number of foreign tourists to visit Hangzhou, so in the scenic area we can provide multi-language warning sign attentions to increase their safety awareness and meet their safety needs. As for large scenic spots like the West Lake and other water areas, every year visitors fall into the water. So we have to establish safety infrastructure to prevent visitors falling into water.

(5) Shopping. Requests for increasing autonomy of shopping accounts for a larger proportion. That problems exist not only in Hangzhou, but also in many other tourist cities of China. Some problems are even serious in other cities that government has already increased the crackdown on coercive consumption in recent years, and requests that enterprises must ensure tourists property safety against deliberate fraud to customer.

(6) Entertainment. Most tourists have requests for safety needs of recreational facilities and operational level of staffs. So we should irregularly check amusement facilities of parks and shut down unstandardized facilities which are dangerous to tourists. Visitors reflect that there are irregularities existing in Songcheng Amusement Park. Against this kind of situations, we should warn staffs and improve their safe operation levels in order to dispel customers' concerns.

\section{Enhance guidance toward tourists}

As for needs part of tourism security, tourists have a strong sense of security risk about lack of safety awareness and poor physical quality. So we have to remind tourists of improving their safety consciousness through message, advertisement, maps as well as travel brochure and we also should eliminate their insecurity via a lot of ways. As for tourism consulting department, we must do a good job in consulting services about tourist travel safety at propaganda windows.

\section{Acknowledgements}

This work was financially supported by the Teaching Methods and Teaching Means Reform Projects of Xi'an University of Science and Technology (ZX16064), and Philosophy and Social Sciences Prosperity Development Project of Xi' an University of Science and Technology（2016SY03）

\section{References}

[1] John.F, Yeganeh.M. Tourism Activity, Terrorism and Political Instability within the Commonwealth: The cases of Fiji and Kenya [J].International Journal of Tourism Research, 2008(10):537-556.

[2] Konstantinos.D, Alim.K.Regional Effects of Terrorism on Tourism in Three Mediterranean Countries [J].Journal of Conflict Resolution,2003(47):621-641. 
[3] Jorge . E . A, Carmelo . J . L. The Impact of Terrorism on Tourism Demand [J]. Annals of Tourism Research, 2008, 35(2):299-315.

[4] Yuksel A., Yukse F.Shopping Risk Perceptions: Effects on Tourists' Emotions, Satisfaction and Expressed Loyalty Intentions [J].Tourism Management, 2007, (3) .

[5] Kwaku Adutwum Boakye, Tourists' views on safety and vulnerability. A study of some selected towns in Ghana [J]..Tourism Management, 2012, 33( 2) : 327-333.

[6] George.R.Tourist's Perceptions of Safety While Visiting Cape Tow [J]. Tourism Management, 2003,(3) .

[7] Leppa A., Gibsonb H.. Tourist Roles, Perceived Risk and International Tourism [J]. Annals of Tourism Research, 2003, (3) .

[8] SNMEZ, SEVIL F. Tourism in crisis: managing the effects of terrorism [J]. Journal of Travel Research, 1999, 38 ( 1): 13-18.

[9] World Tourism Organization.Tourist Safety and Security: Practical Measures for Destinations [J].Tourism Management, 1997, 18( 6) : 407-413.

[10] Mieczkowski Z.Environmental Issues of Tourism and Recreation.Lanham:Press of America, 1995.

[11] George R. Tourist's perceptions of safety and security while visiting Cape Town.Tourism Management,2003,24(5):575 585.

[12] HU Hua,SONG Bao-ping .Decision making model of tourism shopping under the influence of perceived risk [J]. Statistics and Decision, 2009, (22)(in Chinese)

[13] DEN Bing,WU Bi-hu,CAI Li-ping.Summarize of domestic and foreign research on crisis management of tourism industry[J].Tourism Science ,2004,18(1):1-8(in Chinese)

[14] LI Rui-xia,XUE Hui-qun ,ZHENG-Manwei.The influence of political unrest in Thailand on tourism and Its Countermeasures[J].Tourism Research, 2010,2(2):30-35(in Chinese)

[15] ZHENG Xiang-min, ZOU Yong-guang .A study on Sino-Thailand's Tourism Emergency Disposal and Cooperative Mechanism[J].Journal of Huaqiao University,2013(2):36-44(in Chinese)

[16] ZHAO Xiao-min,DAI Guang-quan.Impacts of Terrorist Behaviors on Destination Coutries Inbound Tourism Case Study on Turkey[J].Journal of Guilin Institute of Tourism,2002,13(1):77-85(in Chinese)

[17] ZHU Ming-xia, ZHU Jing.The Impact of Terrorist Incidents on Tourism[J].Commercial Times, 2006 (25) : 96-98(in Chinese)

[18] CHEN Jin-hua,HE Qiao-hua.On Island Tourism Safety Based on Tourists's Peception - A Case Study of Meizhou Island[J]Journal of Ocean University of China,2010:38-42(in Chinese)

[19] ZOU Yong-guang,ZHENG Xiang-min .Study on the Universal Applicability of the Senses of Tourist Security Evaluation Model:Emprical Evidence from Three Types of Tourism Destination[J]. Journal of Beijing International Studies University, 2013, 219(7):63-71(in Chinese) [20] LIU Hong-ying, MA Yao-feng .Tourism Security based on Tourism Apperceive Security index -- Take the Six Top Tourism Cities as Examples [J]. Journal of Arid Land Resources and Environment, 2008, (1) (in Chinese)

[21] KONG Bang-jie.Tourism Safety Management[M]. Shanghai : Shanghai People's Publishing House, 2015.08(in Chinese)

[22] REN Xue -hui, WANG Yue. Designing the System of Precaution and Emergency Rescue Decision for Touring Safety Accidents of Coastal City[J]. Progress in Geography, 2005, 24(4): 123-128(in Chinese)

[23] FAN Chun. Study on the Construction and Promotion of Chongqing Tourism Image Based on Grounded Theory -- from the Perspective of Network Text and Realistic Promotion[J]. Travel Forum,2017,(01):101-110(in Chinese) 
[24] ZHAO Zhong-jun,SUN Xia. Study on the Influencing Factors of Outbound Tourist Satisfaction Based on Grounded theory -- a Case Study of Tuniu Online Reviews[J]. Journal of Xiangtan University,2015,(05):87-91(in Chinese)

[25] ZHANG Tian-wen,WU Ming-yuan. The Constitution of Tourism Well-being Based on a Grounded Theory Analysis of Internet Travel Blogs[J]. Tourism Tribune, 2014, 29(10): 51-60(in Chinese) 